Bull. Mater. Sci., Vol. 17, No. 6, November 1994, pp. 1079-1089. (C) Printed in India.

\title{
Crystallization of polyphenylene sulfide
}

\author{
$J$ P JOG*, NEELIMA BULAKH and V M NADKARNI \\ Chemical Engineering Division, National Chemical Laboratory, Pune 411008 , India
}

\begin{abstract}
The properties of molded PPS parts are dependent on the crystalline morphology developed during processing. Even though processed under identical conditions, the crystalline morphology may differ owing to the differences in the crystallization process. The crystallization behaviour of a polymer is known to depend on its molecular architecture which in turn depends upon polymerization process. Thus the study of the crystallization behaviour of polymer with reference to its molecular architecture is essential for obtaining product with desirable properties. In the present paper, the crystallization behaviour of two grades of polyphenylene sulfide was investigated using differential scanning calorimetry (DSC). An attempt has been made to explain the differences in the crystallization behaviour of PPS samples on the basis of the differences in their molecular architecture. The structural differences of PPS manifest themselves in terms of the depression in the equilibrium melting point, retardation of nucleation and overall crystallization rate and coarsening of spherulitic texture.
\end{abstract}

Keywords. Polyphenylene sulfide; crystallization; curing; morphology.

\section{Introduction}

Polyphenylene sulfide (PPS) is a high performance engineering plastic with excellent thermomechanical properties, good processibility, dimensional stability and chemical resistance (Hill and Brady 1988). Although it exhibits good insulating properties, it can also be made conducting upon doping (Elsenbaumer and Schacklette 1982; Frommer et al 1983). It is mainly used in high performance composites, which are used in diverse applications such as aerospace, nuclear plants, radiation equipment, particle physics generators and medical equipment (O'Donnel 1989)

PPS can be synthesized by two methods of polymerization viz. Macallum and Lenz polymerization (Lenz and Handlovits 1960). Macallum polymerization is a heterogeneous reaction of one or more polybaloaromatic compounds with sulfur and sodium carbonate. The product obtained by this method is mainly branched or lightly crosslinked, whereas Lenz method consists of condensation polymerization of alkali metal salts of $p$-halothiophenols giving a linear structure of PPS. The polymer which is obtained by any of the above two methods is generally a low molecular weight polymer and its molecular weight can be increased by solid state polymerization (Dix 1985). A high molecular weight polymer suitable for injection molding can also be obtained without the solid state polymerization step (Hill $\mathrm{Jr}$ 1979). Thus the differences in the synthesis processes can lead to differences in the molecular architecture of PPS.

The properties of molded PPS parts are dependent on the crystalline morphology (Brady 1976; Kohlepp and Kunst 1989). The morphology developed during processing is governed by the crystallization process. It has been well documented that the

*To whom all correspondence should be addressed 
crystallization behaviour is dependent on the processing conditions and inherent crystallization behaviour of the polymer. The crystallization behaviour of a polymer is known to depend on its molecular architecture defined in terms of linearity, molecular weight distribution (MWD), degree of branching etc. Since chemical structure parameters are influenced by the polymerization process, it would be interesting to monitor the changes in the crystallization behaviour of PPS manufactured by two different companies in order to elucidate the differences in their structure. There have been lew reports on the effect of structure on the crystallization process of PPS (Jog and Nadkarni 1985; Lovinger et al 1985; Lopez and Wilkes 1985; Lopez et al 1989; Budgell and Day 1991; Cebe 1992; Neelima Bulakh et al 1993a). However, a comparative study of the crystallization behaviour is seldom reported.

The present work attempts to explain the observed differences in the isothermal crystallization behaviour of PPS polymers obtained from different sources on the basis of the differences in their molecular architecture.

\section{Experimental}

Poly (phenylene sulfide) (PPS), grades Ryton, V-I supplied by Phillips Petroleum (Singapore) (PPS 1) and Fortron, W203 supplied by Hochest Celanese (USA) (PPS 2) were used for the investigation. The samples were analyzed for their thermal and crystallization behaviour by differential scanning calorimetry (DSC) and also by other analytical techniques such as thermogravimetric analysis (TGA) and optical microscopy (OM).

\subsection{Differential scanning calorimetry (DSC)}

The non-isothermal and isothermal crystallization studies were carried out using Perkin Elmer DSC 2 equipped with thermal analysis data station (TADS). The melting and crystallization parameters were determined by recording DSC scans at a heating and cooling rate of $10^{\circ} \mathrm{C} / \mathrm{min}$ in nitrogen atmosphere respectively. The temperature and cnergy scales were calibrated using standard procedures. The melting and crystallization parameters, such as melting point $\left(T_{m}\right)$, heat of fusion, $\left(\Delta H_{f}\right)$, temperature of crystallization $\left(T_{c}\right)$ and heat of crystallization $\left(\Delta H_{c}\right)$ were used for comparing the two grades.

For non-isothermal crystallization, the samples were heated to $310^{\circ} \mathrm{C}$ and then cooled at different cooling rates ranging from 2.5 to $40^{\circ} \mathrm{C} / \mathrm{min}$. The exothermic peaks recorded were then analyzed as per the procedure described earlier (Neelima Bulakh et al 1993b).

For isothermal crystallization the sample was heated to melt at temperature $20^{\circ} \mathrm{C}$ above the melting point for destroying the residual nuclei. It was held at that lemperature for a dwell time of $2 \mathrm{~min}$. The sample was then quenched at a rate of $160^{\circ} \mathrm{C} / \mathrm{min}$ to a predetermined crystallization temperature, $T_{c}$, at which the crystallization exotherm was recorded on a time base. The exothermic crystallization peak was then analyzed to determine the total crystallization time $\left(t_{c}\right)$ and induction time $I_{1}$. The crystallization data were further analyzed and the crystallization parameters were calculated using Avrami theory (Avrami 1939, 1940, 1941). 


\subsection{Optical microscopy (OM)}

The samples were prepared by melt pressing PPS powders between a glass microscope slide and a cover slip and maintained at this temperature to ensure uniform melting. The siunples were then transferred to the hot stage and crystallized isothermally at the same tempcratures for both the PPS samples. The photomicrographs were then taken using Leica wild MPS 52 with automatic exposure unit on a Leica polarized light microscope.

\subsection{Thermogravimetric analysis}

Thermogravimetric analysis was carried out using Netzsch-409 thermal analyzer at a heating rate of $10^{\circ} \mathrm{C} / \mathrm{min}$ in nitrogen.

\subsection{Curing studies}

The samples were kept in preheated air circulatory oven at $385^{\circ} \mathrm{C}$ and werc taken out after 5, 15 and $45 \mathrm{~min}$. The samples were then allowed to cool to room temperature. The cured samples were then analyzed using DSC.

\section{Results and discussion}

\subsection{Melting and crystallization behaviour}

The DSC heating and cooling scans for PPS 1 and PPS 2 are shown in figures 1a and b, respectively. Since the as received polymers are used, the melting behaviour exhibit the crystallinity and the morphology of PPS which is developed as a result of the crystallization process during polymerization. It is observed from figure 1a that the two samples exhibit distinct melting peak temperatures at $284^{\circ} \mathrm{C}$ and $293^{\circ} \mathrm{C}$ for PPS 1 and PPS 2 respectively. The higher value of the melting peak temperature for the sample PPS 2 relative to PPS 1 indicates higher stability and perfection of the crystallite (Wunderlich 1980). The values of the heat of fusion are 49.1 and $55.4 \mathrm{~kJ} / \mathrm{kg}$ for PPS 1 and PPS 2 respectively indicating different extent of crystallization for the two samples. This difference may be attributed to the extent of crystallization during polymerization.

The crystallization during cooling takes place at a higher temperature for PPS 2 $\left(253^{\circ} \mathrm{C}\right)$ relative to that for PPS $1\left(246^{\circ} \mathrm{C}\right)$. This might be due to the higher inelting peak temperature of PPS 2 relative to that of PPS 1.

The melting behaviour of the melt-crystallized samples (samples crystallized during cooling at a rate of $10^{\circ} \mathrm{C} / \mathrm{min}$ ) was studied using the rehcating scans. When the melting parameters are compared, it was observed that PPS 1 exhibits a melting peak temperature of $283 \mathrm{C}$ and heat of fusion of $38.2 \mathrm{~kJ} / \mathrm{kg}$ as compared to $286^{\circ} \mathrm{C}$ and $45.8 \mathrm{~kJ} / \mathrm{kg}$ for PPS 2 . Thus, even when crystallized under identical conditions, the two PPS samples exhibited different melting peak temperatures and extent of crystallization.

Since the two polymers exhibited distinct melting peak temperatures (even for 

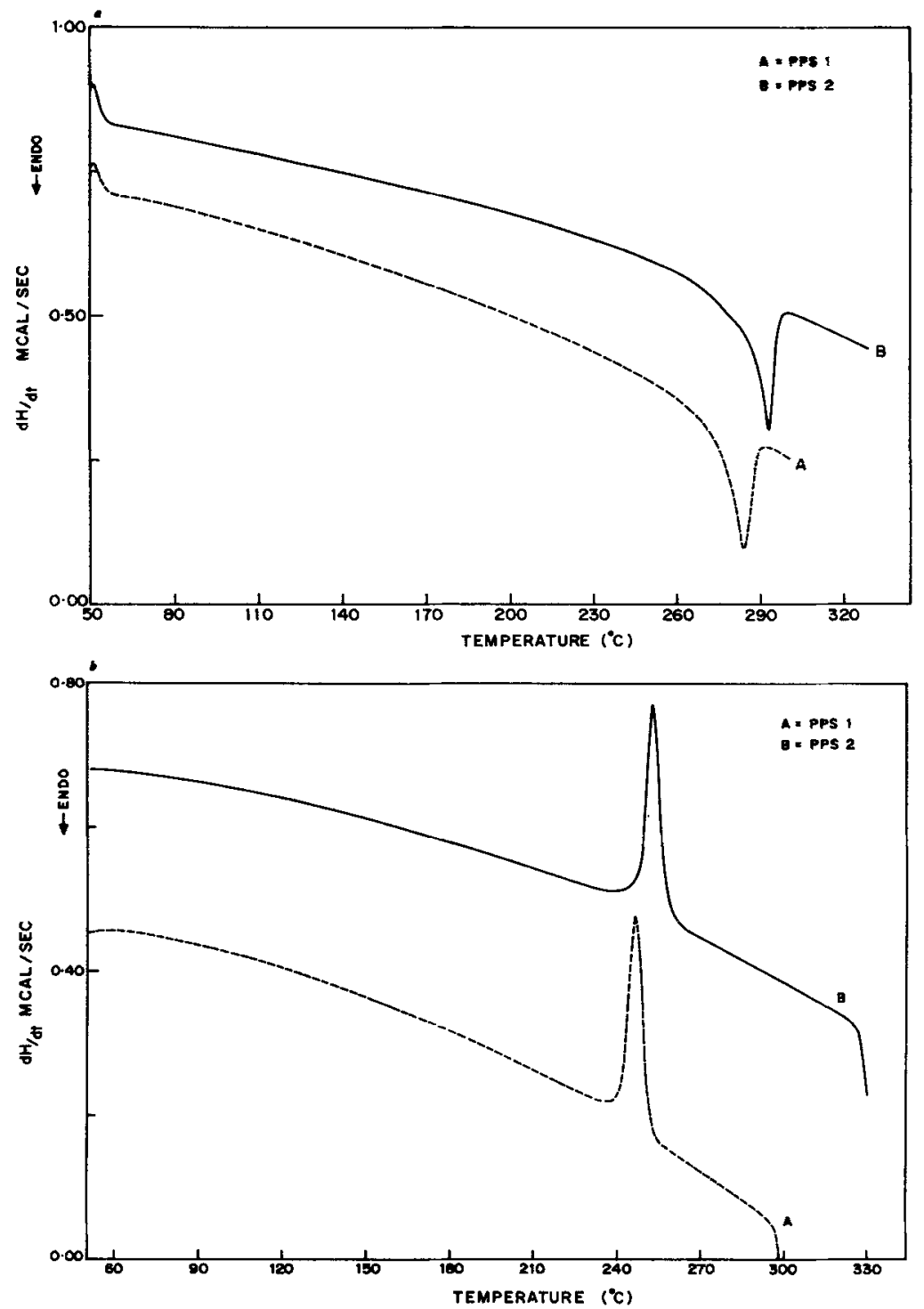

Figure 1. a. DSC heating scans for PPS 1 and PPS 2 samples and b. DSC cooling scans for PPS 1 and PPS 2 samples.

the melt crystallized samples), the equilibrium melting points of PPS samples were determined using the method suggested by Hoffmann and Weeks (1962). The method consists of melting peak temperature measurement of isothermally crystallized polymer samples at selected supercoolings. The experimental melting points are then plotted as a function of crystallization temperature. Figure 2 shows the $T_{c}$ vs $T_{m}$ plots for PPS 1 and PPS 2. A straight line relationship between melting and crystallization temperatures is observed. This line is extrapolated to $T_{c}=T_{m}$, and 


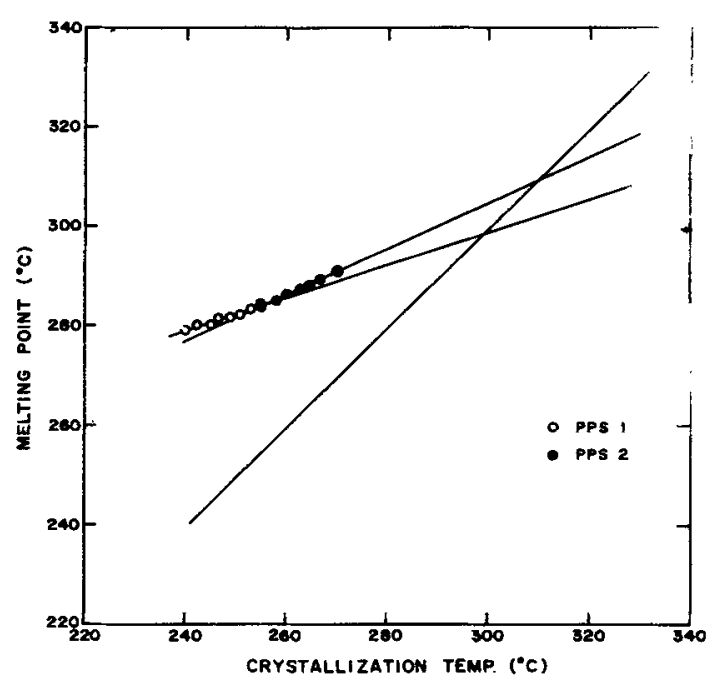

Figure 2. Hoffmann-Weeks plots for PPS 1 and PPS 2 samples.

the point of intersection represents the thermodynamic melting point $\left(T_{m}^{\circ}\right)$. The calculated values of $T_{m}^{\circ}$ for PPS 1 and PPS 2 were $298^{\circ} \mathrm{C}$ and $308^{\circ} \mathrm{C}$ respectively. The value of $T_{m}^{\circ}$ for PPS 1 was lower than the value of $303^{\circ} \mathrm{C}$ reported for low molecular weight Ryton V-I (Lovinger et al 1985). However, for PPS 2 it was found to be comparable to the value reported for high molecular weight PPS (Lopez and Wilkes 1988). It has been reported that branching decreases the perfection of the crystals resulting in lowering of equilibrium melting point of the polymers. In case of LLDPE, a monotonic decrease in the melting point with increase in branch concentration has been reported by Mandelkern and Maxfield (1979). Similar drop in equilibrium melting point has also been noted by Lopez et al (1989) for linear and branched PPS. The lower value of $T_{m}^{\circ}$ for PPS 1 can thus be attributed to lower perfection of the crystals due to the presence of branching.

The non-isothermal crystallization behaviour of the two PPS samples was studied by crystallizing the samples during cooling at different cooling rates. As reported in our earlier publication, the information regarding the crystallizability can be derived from the non-isothermal crystallization data (Neelima Bulakh et al 1993b). Figure 3 illustrates the variation of the degree of supercooling $\left(T_{m}^{\circ}-T_{c}\right.$ onset) with cooling rate. It can be seen that the data can be fitted to a straight line equation. The values of the intercept for PPS 1 and PPS 2 were found to be $19^{\circ} \mathrm{C}$ and $13^{\circ} \mathrm{C}$ respectively. The higher value of intercept for PPS 1 suggests that the polymer is less crystallizable as compared to PPS 2 . This may be either due to different molecular weights and/or differences in the chemical structure (presence of branching). Since both these factors would influence the crystallization process, the isothermal crystallization behaviour of the two grades of PPS was investigated.

The isothermal crystallization study was carried out over a temperature range of $240^{\circ}-260^{\circ} \mathrm{C}$ for PPS 1 and $255^{\circ}-270^{\circ} \mathrm{C}$ for PPS 2. The experimental data were analyzed using Avrami's theory (Avrami 1939, 1940, 1941). The induction time, $t_{i}$ and the crystallization half time, $t_{0.5}$ have been chosen as characteristic parameters 


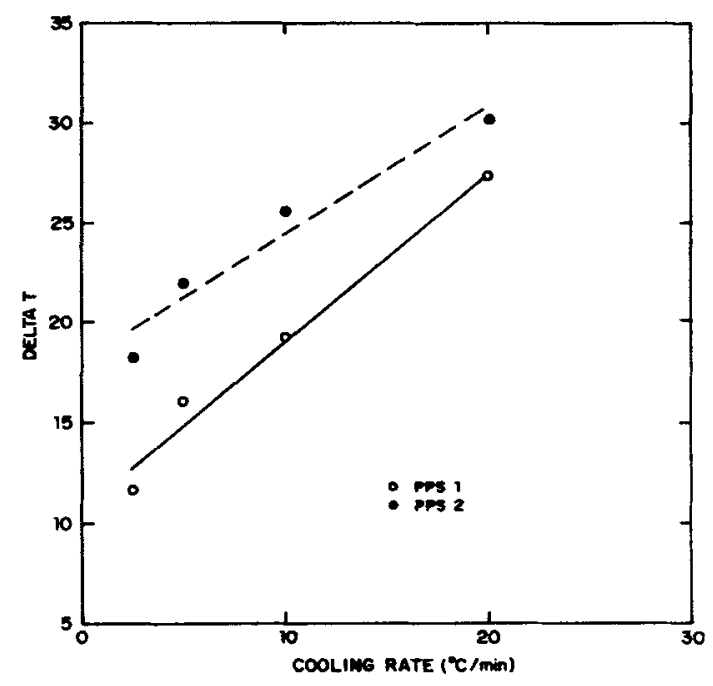

Nigure 3. Vartation of 1 with coong rate for PPS 1 and PPS 2.

for the crystallization process which represent the onset of nucleation and the overall crystallization rate respectively. Since both the polymer samples exhibited different melting points that are about $10^{\circ}$ apart, the crystallization parameters are compared as a function of the degree of supercooling instead of the temperature of crystallization. The variation of induction time and crystallization half time with the degree of supercooling $(\Delta T)$ is shown in figures 4 and 5 respectively. It is observed that the induction time is lower for PPS 2 over the entire range of supercoolings. Since the induction time represents the characteristic of the nucleation process, the lower values of induction time for PPS 2 suggest that the nucleation of PPS 2 is faster as compared to PPS 1. The variation of the crystallization half time with temperature of crystallization also exhibited similar behaviour indicating that the crystallization rate of PPS 2 is faster than that for PPS 1.

It is well documented that the overall crystallization rate of a polymer decreases with increasing molecular weight. In case of PPS, the overall rate of bulk crystallization was reported to decrease by a factor of $\sim 4$ over the molecular weight $\left(M_{w}\right)$ range of 24000 to 63000 (Lopez and Wilkes 1988) whereas for branched PPS it was 50\% lower than that of linear PPS at comparable molecular weight of about 65000 (Lopez et al 1989). In the present study, the observed difference in the crystallization rate thus may be due to the differences in the molecular weight and/or presence of branching. When the crystallization rate values are compared at equal degrees of supercooling it was observed that the crystallization rate for PPS 1 was an order of magnitude lower than that for PPS 2 (tigure 6). This clearly suggests that PPS 2 sample has a more linear structure as compared to PPS 1. This contention is also supported by the observed higher value of $T_{m}^{\circ}$ for PPS 2 relative to that for PPS 1.

PPS is known to undergo chemical reactions when exposed to high temperatures for prolonged times (Hawkins 1976). Three types of reactions, viz. chain extension, branching and crosslinking are reported. When exposed to temperatures above its 


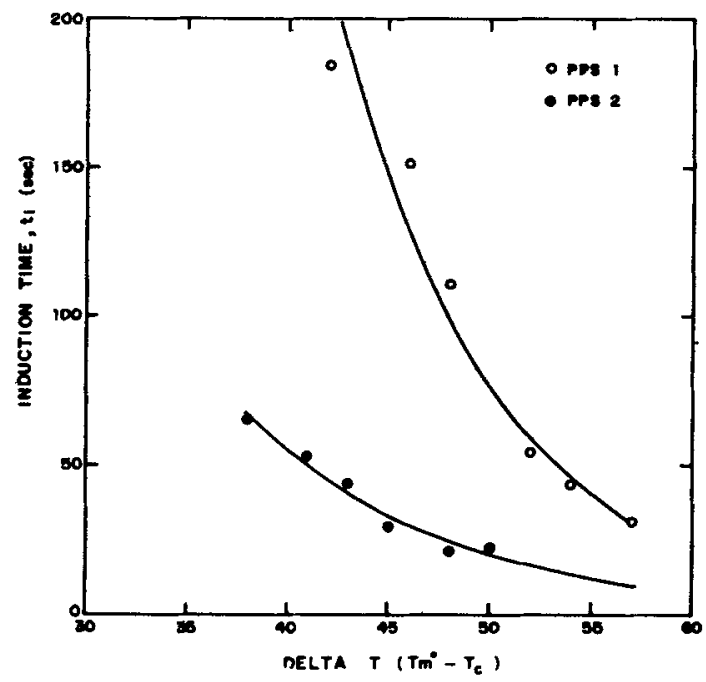

Figure 4. Variation of induction tinke, $T_{i}$ with degree of supercooling for PPS 1 and PPS 2 samples.

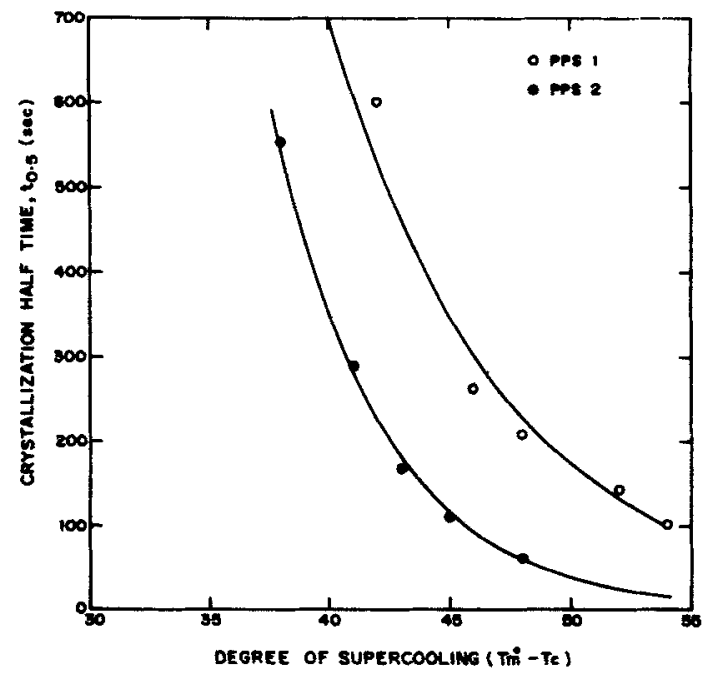

Figure 5. Variation of crystallization half time, $t_{0-5}$ with degree of supercooling $(\Delta T)$ for PPS 1 and PPS 2 samples.

melting point in air, crosslinking of PPS takes place leading to decreased crystallizability and crystallinity (Neelima Bulakh et al 1993a). The rates of change of degree of crystallinity and crystallizability were found to be dependent on the time, temperature and atmosphere. The response of the two PPS grades to the high temperature exposure was studied to elucidate the subtle differences in their chemical structure. The samples of PPS were cured at $385^{\circ} \mathrm{C}$ in air for dwell times ranging 


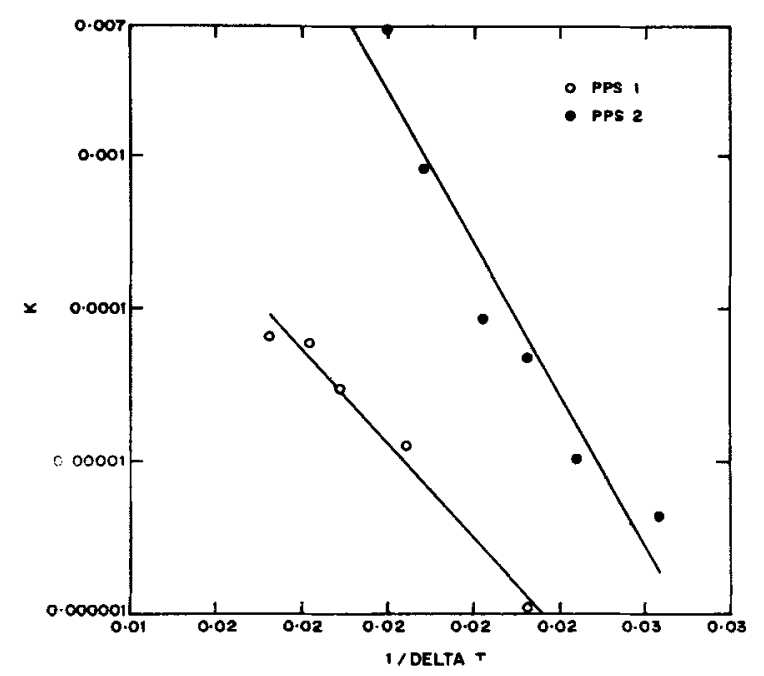

Figure 6. Variation of rate constant $K$ with $1 / \Delta T$.

from 5 to $45 \mathrm{~min}$. The effect of the thermal treatment on the heat of fusion is illustrated in figure 7. It is observed that the heat of lusion which represents the degree of crystallinity of the cured sample decreases more rapidly for PPS 2 sample as compared to PPS 1 sample. The curing or crosslinking of PPS is reported to result in a decrease in the crystallinity and crystallizability (Brady 1976). The decrease in the crystallinity of PPS samples with increase in the dwell time thus represents increased degree of curing. Thus the observed results suggest that the degree of curing for PPS 2 sample is higher relative to that for PPS 1 at any given time indicating better thermal stability of PPS 1. In other words PPS 1 undergoes chemical reactions to lesser extent than PPS 2 at high temperature. Black et al (1967) have compared the thermal stability of linear and branched PPS samples. They have reported that in general, the thermal stability of PPS samples was dependent on the linearity of the polymer: the higher the degree of branching, the more stable the polymer. Thus the results of curing suggest that PPS 1 is having a more branched structure polymer as compared to PPS 2.

The thermogravimetric analysis in nitrogen atmosphere also exhibited a two-stage degradation process for PPS 1 whereas for PPS 2 it was found to be a single degra! lion process as illustrated in figure 8 . The presence of two distinct steps in the TGA is suggestive of two mechanisms of degradation which may be corresponding to the linear and branched chain structure in PPS 1.

The spherulitic morphology of the two PPS samples was observed using polarized light optical microscope. The micrographs for samples of PPS 1 and PPS 2 crystallized at $235^{\circ} \mathrm{C}$ are shown in figure 9 at equal magnification using cross polars. It can be seen that both the samples exhibited well defined spherulitic structures. It is also clear from the micrographs that the spherulites differed in size. The spherulite size is larger for PPS 1 than that for PPS 2. It was already observed that the nucleation process for PPS 1 was slower as compared to that for PPS 2. Since the nucleation is slower, the number of nuclei growing at a 


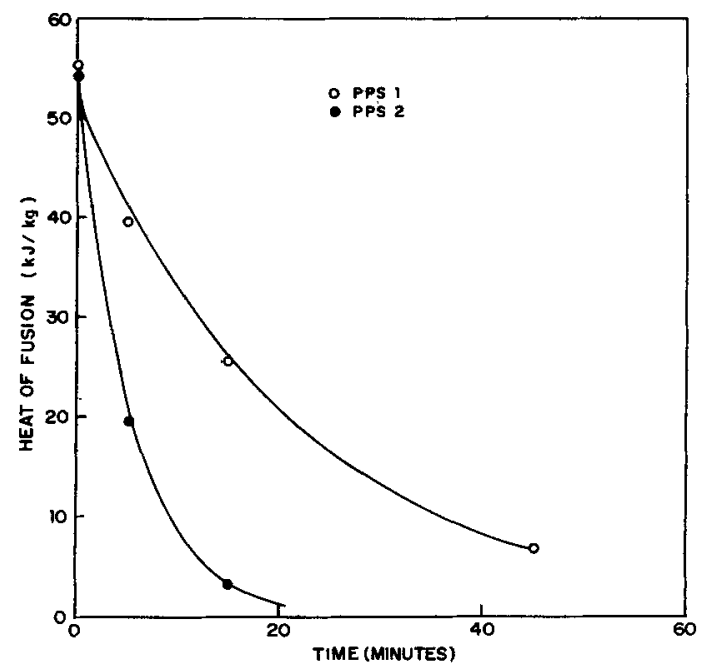

Figure 7. Variation of heat of fusion with dwell time for PPS samples cured in air at $385^{\circ} \mathrm{C}$.

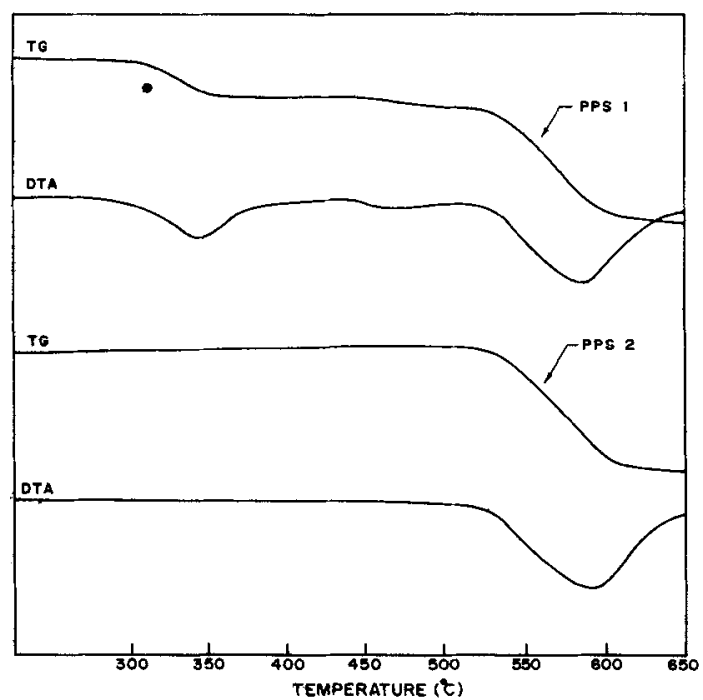

Figure 8. TGA scan for PPS samples.

particular crystallization temperature would be less for PPS.1 sample and as a result the size of the spherulites would be larger relative to the sample with bigher nucleation rate. The spherulites of the two PPS samples also exhibited difference in textures. The texture of a spherulite can be defined as coarse or fine depending upon the cross section of the fibrils. The spherulites of PPS 2 exhibit fine texture as compared to those of PPS 1. The coarseness of the spherulitic structure for 

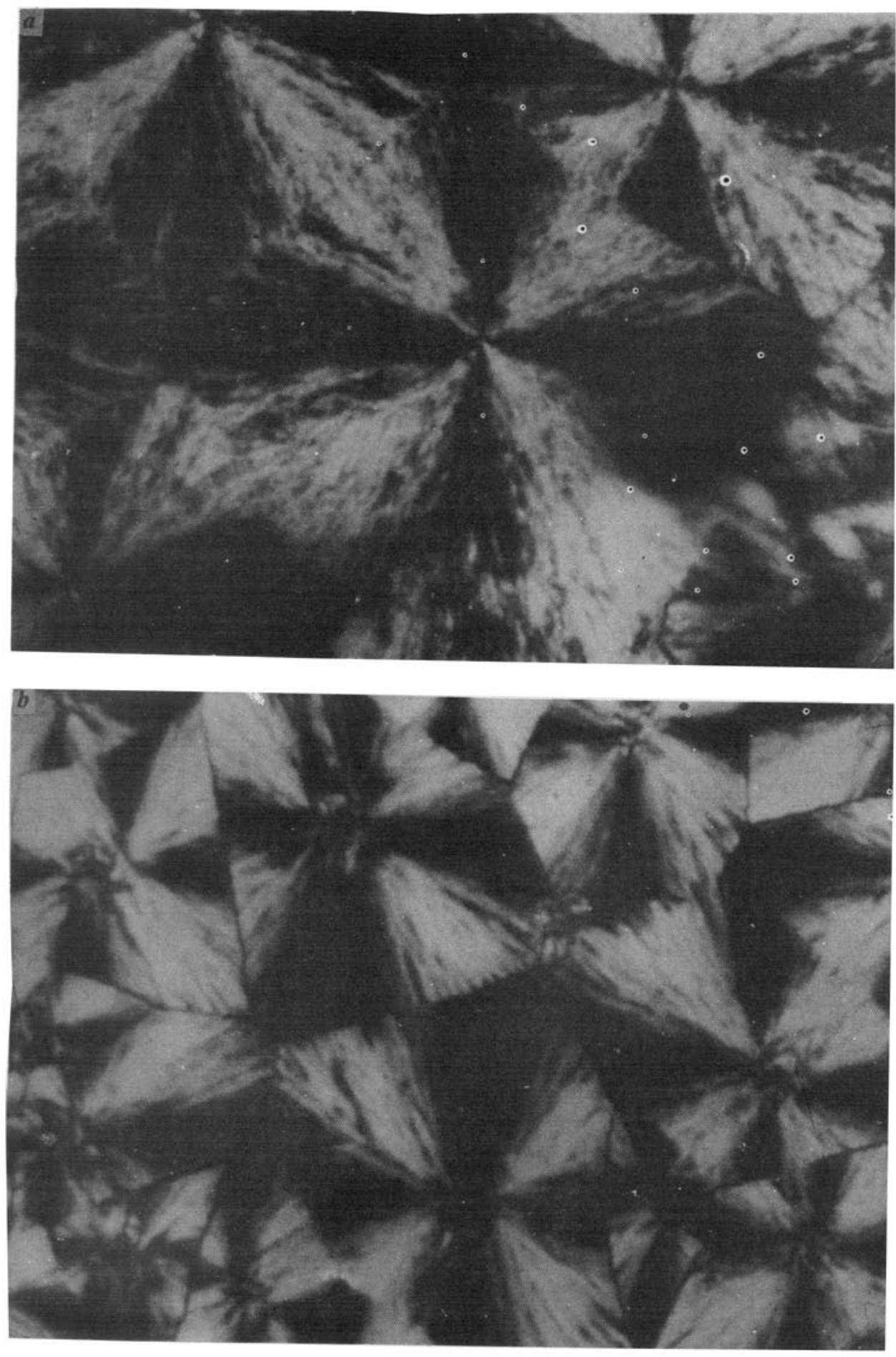

Figure 9. Optical micrographs for a. PPS 1 and $\mathbf{b}$. PPS 2 samples isothermally crystallized at $235^{\circ} \mathrm{C}$. 
PPS 1 may be attributed to the presence of non-crystalline regions between growing fibrils (Keith and Padden Jr 1963).

\section{Conclusions}

The differences in the thermal and crystallization behaviour of PPS samples of different manufactures are attributed to the possible differences in the molecular architecture. The structural differences manifest themselves in terms of the depression in the equilibrium melting point, retardation of nucleation and overall crystallization rate and coarsening of spherulitic texture. The linear polymer exhibited higher equilibrium melting point, faster nucleation and higher overall crystallization rate as compared to the branched polymer. The high temperature curing behaviour also indicated similar changes in the response parameters. Thus, techniques such as TGA and nonisothermal crystallization can be used to ascertain changes in molecular architecture of polymers with the same chemical structure. Since the crystallization and curing, both these processes are important from the application point of view and a thorough study of PPS grades is required to obtain a product with desired properties.

\section{References}

Avrami M 1939 J. Chem. Phys. 71103

Avrami M 1940 J. Chem. Phys. 8212

Avrami M 1941 J. Chem. Phys. 9177

Black R M, List C F and Wells R J 1967 J. Appl. Chem. 17269

Brady D G $1976 \mathrm{~J}$. Appl. Polym. Sci. 202541

Budgell D R and Day M 1991 Polym. Engg. Sci. 311271

Cebe P 1992 Polymer 332312

Dix J J 1985 Chem. Eng. Prog. 42

Elsenbaumer R L and Schacklette L W 1982 J. Polym. Sci. Polym. Phys. Edn. 201781

Fromner J E, Elsenbaumer R L, Echardt H and Change R R 1983 J. Polym. Sci. Lett. Edn. 2139

Hawkins R T 1976 Macromolecules 9189

Hill Jr H W 1979 Indian Engg. Chem. Prad. Res. Dev. 18252

Hill H W and Brady D G 1988 Encycl. Polym. Sci. Engg. II Ed. 11531

Hoffmann J D and Weeks J J 1962 J. Res. Nat. Bur. Stds. A66 13

Jog J P and Nadkarni V M 1985 J. Appl. Polym. Sci. 30997

Keith H D and Padden Jr F J 1963 J. Appl. Phys. 342409

Kohlepp M and Kunst F F 1989 Germ. Plast. 7927

Lenz R W and Handlovits C E 1960 J. Polym. Sci. XLIII 167

Lopez L C and Wilkes G L 1988 Polymer 29111

Lopez L C and Wilkes G L 1989 Polymer 30882

Lopez L C, Wilkes G L and Geibel J F 1989 Polymer 30147

Lovinger A L, Davis D D and Padden Jr F J 1985 Polymer 261595

Mandelkern L and Maxfield J 1979 J. Polym. Sci. Polym. Phys. 171913

Neelima Bulakh, Jog J P and Nadkarni V M 1993a J. Macro. Sci. Phys. B32 275

Neelima Bulakh, Jog J P and Nadkarni V M 1993b Adv. Polym. Technol. 1273

O'Donnell J H 1989 in Effects of radiation on high technology polymers (eds) E Reichmanis and J H O'Donnell (Washington: American Chemical Society)

Wunderlich B 1980 in Macromolecular physics (New York: Acadenic Press) Vol. 3 